\title{
PROGRAMAS DE TRANSFERENCIA CONDICIONADA FRENTE A FRENTE: LOS CASOS DE CHILE, PARAGUAY $Y$ COLOMBIA (2000-2012)
}

\author{
Cecilia Osorio Gonnet ${ }^{(\cdot)}$ \\ José Miguel Vergara Hermosilla $(\cdot \cdot)$ \\ Universidad Alberto Hurtado (Chile)
}

\section{RESUMEN}

La ola de difusión de los Programas de Transferencia Condicionada (PTC) en América Latina generó un grupo de programas sociales con características comunes, pero también ciertas divergencias. Este artículo ofrece una mirada comparada a los programas de tres países: Chile, Colombia y Paraguay, analizando sus componentes y la coherencia interna entre los fines y medios de las iniciativas. Los hallazgos evidencian diversidad en los programas, diferentes grados de coherencia entre los fines perseguidos y medios utilizados, así como indicios de transferencia de componentes entre países. Todo ello plantea desafíos para la comprensión de los procesos de formulación de políticas sociales en América Latina.

\section{PALABRAS CLAVE:}

Programas de Transferencia Condicionada (PTC), América Latina, fines perseguidos y medios, transferencia de políticas.

\footnotetext{
(•)E-mail: cosorio@uahurtado.cl

(••) E-mail: jm.vergara.hermosilla@gmail.com
}

\section{ABSTRACT}

The wave of diffusion of the Conditional Transfer Programs (CCTs) in Latin America generated a group of programs with common characteristics, but also certain divergences. This article offers a comparative look at the programs of three countries: Chile, Colombia and Paraguay distinguishing their components and the internal coherence between aims and means. The findings show diversity in the programs, different levels of coherence between the aims pursued and means used, as well as evidence of process of transfer among countries. All of it poses challenges for the comprehension of the social policy making process in Latin America.

\section{KEY WORDS:}

Policy Aims, Policy Tools, Conditional Cash Transfer programs, Latin America and Policy Transfer. 


\section{INTRODUCCIÓN ${ }^{1}$}

Durante los años noventa las políticas sociales en América Latina experimentaron una serie de transformaciones que implicaron un fuerte cambio de paradigma. Esto, debido a que en la postrimería de los años ochenta se inician reformas estructurales que implicaron una reformulación del rol del Estado, de los privados y la sociedad civil (Franco 1996, Sottoli, 2002). Este nuevo paradigma de las políticas sociales concentró sus objetivos en la superación de la pobreza, focalizando por tanto en la población en esta situación los programas y beneficios ${ }^{2}$. Es en este contexto que emergen los Programas de Transferencia Condicionada (PTC) como experiencias iniciales en Brasil y México (Cohen y Franco, 2006), con el objetivo entregar un apoyo monetario a las familias pobres a condición de que estas utilizasen determinados servicios públicos del ámbito de la salud y/o educación (Cecchini y Madariaga, 2011). Durante el fin de los años noventa y hasta el 2010, estas iniciativas se diseminaron por la región en un proceso de difusión (Sugiyama, 2011 y Osorio, 2014), siendo implementados por 18 de los 20 países de América Latina ${ }^{3}$, y beneficiando a más de 130 millones de personas al año 2015 (Cecchini y Atuesta, 2017).

Es posible distinguir en los programas dos componentes esenciales que están presentes en la mayoría de estos: la entrega de bonos en dinero a la 
mujer identificada como jefa de hogar, y la condicionalidad aplicada al ámbito educacional y/ al de la salud (Osorio, 2014; Friszbein y Schady, 2009; Cecchini y Madariaga, 2011). Ahora bien, también se detectan otros componentes solo en algunos programas, tales como apoyo sicosocial para el grupo familiar (Osorio, 2014). Asimismo, se observa variación en cuanto a instrumentos vinculados a la implementación de las iniciativas, tales como los mecanismos de control de las condicionalidades, los tipos de penalización, la institucionalidad responsable y si el programa forma parte o no de un sistema de protección social (Osorio, 2014).

Esta variación en los componentes y características, indican que existe un espacio posible de profundizar en el análisis en cuanto a identificar las similitudes y diferencias entre los programas que han surgido en la ola de difusión. Por ejemplo, Cecchini y Martínez (2011), a partir de los énfasis que detectan en los componentes de los PTC, los clasifican entre programas con condicionalidad blanda, fuerte y programas con enfoque de protección social (Cecchini y Martínez, 2011). Entonces, si bien el "objeto" de difusión posee características comunes, existen variaciones que es preciso identificar y sistematizar, para avanzar en la comprensión de estas significativas iniciativas en el ámbito social de la región.

Junto con ello, la literatura acerca de los programas señala la incidencia de algunas iniciativas en otras. "Puede destacarse el impacto, en general, de Bolsa Familia-Brasil y Oportunidades-México, y recientemente de Chile SolidarioChile, en los nuevos programas PTC que se han ido generando con rapidez en América Latina especialmente a partir del año 2000" (Valencia 2008: 502). Este último, el Chile Solidario (CHS), nace en el año 2002 y tenía como objetivo promover la integración de las familias en situación de extrema pobreza a las redes sociales del Estado y facilitar así su acceso a mejores condiciones de vida (Ley 19.949, 2004). Contenía cuatro ejes: bono de protección a la familia, apoyo psicosocial personalizado a las familias beneficiarias, subsidios monetarios garantizados y acceso preferente a programas de promoción social (Cohen y Franco, 2006). Existe evidencia de que algunos de estos componentes constituyeron una innovación - como el componente de apoyo sicosocial- y que posteriormente se observan en algunos programas de América Latina Paraguay, Guatemala, Colombia, Panamá y el Caribe ${ }^{4}$ (Valencia, 2008; Peck, 2015; Cechinni y Martínez, 2011). Por ello, en este trabajo se pondrá atención a identificar aquellos componentes innovadores que pudieron ser transferidos desde este programa a otros países.

Considerando lo anterior, un primer objetivo de este trabajo es analizar las características comunes y divergentes de los PTC en América Latina. Para este 
análisis, se utilizará la distinción entre los "fines perseguidos" (policy mains) y los «medios" (policy tools) (Hall, P. 1993; Howlett y Cashore, 2009), la cual permitirá analizar la coherencia interna de los programas. También se pondrá atención a los componentes presentes en los PTC, lo que permitirá profundizar en el análisis y así mismo, avanzar al segundo objetivo. Este es, identificar si destacan componentes innovadores en el conjunto de programas y que pudieran haber sido objetivo de transferencia. Este ejercicio constará de una mirada a nivel regional y luego se focalizará en la comparación de los casos de Chile, Paraguay y Colombia, durante el período $2000-2012^{5}$.

La estructura de este trabajo cuenta con cuatro partes. El primer apartado caracteriza los Programas de Transferencia Condicionada que se difundieron en la región. En segundo lugar, se presenta el enfoque escogido para realizar la comparación de los programas, destacando la distinción entre "fines perseguidos" (policy mains) y los "medios" (policy tools) (Hall, P. 1993; Howlett, M. \& Cashore, B. 2009). Junto con ello, se presenta el marco metodológico y la perspectiva de análisis que permitirá la comparación en profundidad de los casos de Chile, Paraguay y Colombia. A continuación, se describen las principales características de estos tres PTC, así como también sus componentes, los que serán analizados a partir de la perspectiva propuesta. Finalmente, se entregarán los hallazgos de este ejercicio y se plantearán futuros desafíos e interrogantes a tratar en la materia.

\section{LOS PROGRAMAS DE TRANSFERENCIA CONDICIONADA EN AMÉRICA LATINA Y SUS COMPONENTES}

Los Programas de Transferencia Condicionada emergen en América Latina durante la década de los noventa, cuando países como Chile, Argentina, Perú, Bolivia, Paraguay y Uruguay iniciaban sus procesos de transición y consolidación de la democracia. La característica principal de los PTC es la provisión de dinero en efectivo o en especies a los hogares de bajos ingresos, a condición de que las familias utilicen determinados servicios públicos, entre los que se encuentran salud y/o educación. En ese sentido, es posible observar un componente tradicional de la política social, esto es, una prestación monetaria directa o en especies a un grupo definido de personas. Ahora bien, a diferencia de otras políticas de transferencias, se observa que la condicionalidad implica la demanda de una acción específica por parte del beneficiario y que lo habilita (solo en caso de cumplirla) como receptor del programa (Osorio, 2014). Bajo esta lógica, la 
corresponsabilidad establece que el Estado, en este tipo de política, asume el deber de procurar la transferencia y los bienes y servicios adecuados, y la familia beneficiaria se compromete, a su vez, a hacer uso de estos últimos (ver Tabla 1). Por tanto, marca diferencias respecto de otros programas para superar la pobreza que se basaban en la entrega de productos (bienes y servicios) sin exigir nada en contrapartida (Cohen y Franco, 2006 y Osorio, 2014).

\section{Tabla 1.}

Los Programas de Transferencia Condicionada en América Latina (1990-2012)

\begin{tabular}{|c|c|c|c|c|}
\hline & País & Nombre programa & Año inicio & Condicionalidades \\
\hline 1 & Argentina & $\begin{array}{l}\text { Asignación Universal por Hijo para } \\
\text { Protección Social (ex Familias por la } \\
\text { Inclusión Social y ex Plan de jefes y } \\
\text { jefas de hogar desocupados) }\end{array}$ & 2005 & $\begin{array}{l}\text { Asistencia a escuelas y chequeos } \\
\text { de salud }\end{array}$ \\
\hline 2 & Bolivia & Bono Juancito Pinto & 2006 & Asistencia escolar \\
\hline 3 & Brasil & $\begin{array}{l}\text { Bolsa Familia (ex Bolsa Alimentación } \\
\text { y Bolsa Escuela) }\end{array}$ & $\begin{array}{l}1995 \\
\text { (piloto) }\end{array}$ & Asistencia escolar y chequeos salud \\
\hline 4 & Chile & Chile Solidario (hoy Ingreso Ético) & 2002 & $\begin{array}{l}\text { Educación, empleo, vivienda, } \\
\text { ingresos, vida familiar, entre otros }\end{array}$ \\
\hline 5 & Colombia & Familias en Acción & 2001 & $\begin{array}{l}\text { Asistencia escolar, chequeos salud } \\
\text { y alimentación }\end{array}$ \\
\hline 6 & Costa Rica & Avancemos (ex Superémonos) & 2000 & Asistencia escolar y chequeos salud \\
\hline 7 & Ecuador & $\begin{array}{l}\text { Bono de Desarrollo Humano } \\
\text { (ex Bono Solidario) }\end{array}$ & 2003 & Asistencia escolar y chequeos salud \\
\hline 8 & El Salvador & Comunidades Solidarias Rurales & 2005 & Asistencia escolar y chequeos salud \\
\hline 9 & Guatemala & Mi familia Progresa & 2008-2012 & Asistencia escolar y chequeos salud \\
\hline 10 & Haití & Ti Manman Cheri & 2012 & Asistencia escolar \\
\hline 11 & Honduras & Programa de asignación Familiar (PRAF III) & 1998 & Asistencia escolar y chequeos salud \\
\hline 12 & México & Oportunidades (hoy Prospera) & $\begin{array}{l}1995 \\
\text { (piloto) }\end{array}$ & Asistencia escolar y chequeos salud \\
\hline 13 & Nicaragua & Red de Protección Social & 2000-2006 & Asistencia escolar y chequeos salud \\
\hline 14 & Panamá & Red Oportunidades & 2006 & Asistencia escolar y chequeos salud \\
\hline 15 & Paraguay & Tekoporâ & 2005 & Asistencia escolar y chequeos salud \\
\hline 16 & Perú & Juntos & 2005 & Asistencia escolar y chequeos salud \\
\hline 17 & $\begin{array}{l}\text { República } \\
\text { Dominicana }\end{array}$ & Programa Solidaridad & 2005 & Asistencia escolar y chequeos salud \\
\hline 18 & Uruguay & $\begin{array}{l}\text { Plan Equidad (ex Ingreso Ciudadano/ } \\
\text { PANES) }\end{array}$ & 2008 & Asistencia escolar y chequeos salud \\
\hline
\end{tabular}

Fuente: versión previa en Osorio (2014), en base CEPAL (2011a), León (2008) y Cecchini y Madariaga (2011). 1: se señala el nombre original del programa y entre paréntesis los nombres posteriores si los hubo. 
Asimismo, los PTC son programas focalizados, ya que la población destinataria son familias - no individuos - pobres o extremadamente pobres con ciertos requisitos adicionales (la existencia en el grupo familiar de niños y adolescentes en edad escolar, lactantes, niños con desnutrición, mujeres embarazadas o en período de lactancia) (Cohen y Franco, 2006: 36). No se aspira a acceder a toda la población, sino que se establecen criterios (socioeconómicos, geográficos, por ejemplo) que delimitan las características del grupo beneficiario (Osorio, 2014).

Una primera aproximación al listado de los programas en la región (Tabla 1) indica la condicionalidad como una característica central y que homologa todas las iniciativas. Esta puede desarrollarse en el ámbito de la educación y/o en el de la salud. Luego, un segundo componente esencial es la entrega de bonos en dinero a la jefa de hogar (mujer) (Osorio, 2014; Fiszbein y Schady, 2009; Cecchini y Madariaga, 2011). De esta forma podemos determinar que estos componentes conforman el cuerpo central de todos los PTC, siendo principalmente la condicionalidad su rasgo más distintivo.

El componente de condicionalidad educacional, correspondiente a la asistencia de niños, niñas y adolescentes a establecimientos educacionales, se encuentra presente en el $100 \%$ de los programas. En relación a la condicionalidad en salud, establecida como la asistencia a controles de salud al día para menores de edad, esta se encuentra presente en el $89 \%$ de los programas de la región. En tercer lugar, podemos identificar la entrega de un bono en dinero o especies a la jefa de hogar, cual está presente en el $100 \%$ de ellos (Ver Tabla 6 en anexo).

Como ya se comentó arriba, también es posible identificar un componente adicional a los tres planteados, que se refiere al beneficio de apoyo psicosocial por parte de profesionales especializados para las familias beneficiarias, como era en el caso de Chile con el Chile Solidario (León, 2008; Osorio, 2014). Adicionalmente, este componente puede contar con un bono o bien asignada para aquellas familias que reciben este beneficio. Sin embargo, esta innovación solo se encuentra presente en el 33\% de los programas presentes en la región.

Asimismo, si se pone atención a otros aspectos vinculados al diseño de los programas y su implementación, se observan también similitudes y divergencias en cuanto a las opciones escogidas e implementadas (Osorio, 2014). Por ejemplo, la mayoría de los programas (16) utilizan el mecanismo de focalización de medios de comprobación (proxy means test), que puede ser complementado con otros medios, como geográfica o a nivel de comunidades (community-based targeting). Por otro lado, en cuanto a los mecanismos de control de las condi- 
cionalidades de educación y de salud, estos pueden realizarse mediante reporte de los establecimientos educacionales y de atención de salud, presente en el $72 \%$ de los programas, o mediante un reporte realizado por los beneficiarios a las oficinas encargadas y entidades del programa, esta última presente en el $28 \%$ de los programas de la región (Ver Tabla 7 en anexo). También se observa variación en cuanto a si el programa es parte de un sistema de protección social existente previamente o que es implementado de manera paralela al PTC. La variación en relación a estos componentes y respecto a los objetivos del programa, confieren - en su presencia o ausencia - de un énfasis de los PTC en cuanto a la protección social. Por último, la mayoría de los programas dependen de los ministerios sociales correspondientes, desde los primeros programas instaurados. Sin embargo, también se aprecian, programas que dependen directamente de la Presidencia (ver Tabla 7).

Cerrando esta descripción y análisis de los PTC, Cecchini y Martínez (2011) proponen clasificar los programas en tres grupos: programas con condicionalidad blanda, fuerte y programas con enfoque de protección social (Cecchini y Martínez, 2011). En este sentido, el primer grupo tiene como objetivo principal asegurar un nivel de consumo básico a las familias pobres a través de la transferencia monetaria, con lo cual se enfoca en la transferencia de ingreso, se establecen sanciones "blandas" al incumplimiento de condicionalidades y se establecen transferencias planas o por composición familiar. En el segundo grupo se tiene como objetivo central promover el capital humano de las personas en situación de pobreza mediante un mayor uso de los servicios de salud y educación. Por lo cual, los objetivos son de largo plazo enfocados en el desarrollo humano y se establece un estricto control de las condicionalidades (seguimiento de los reportes y de penalización dura). Finalmente, el tercer grupo son los sistemas o redes de coordinación programática con condicionalidades. En los objetivos de estos programas se señala, junto con el apoyo monetario o el desarrollo de capital humano, la inclusión de las familias a redes de apoyo estatal y el fortalecimiento de sus capacidades psicosociales. Por tanto, su propósito es conectar a las familias pobres con las distintas prestaciones ofrecidas por programas específicos y así generar un piso de inclusión. Están enfocados en la conexión al sistema de protección social, por lo que la importancia del bono en dinero es muy baja (Cecchini y Martínez, 2011). 


\section{COMPONENTES DEL ANÁLISIS DE LOS PTC: FINES Y MEDIOS}

Una innovación política es en esencia un cambio de política, aunque no todos los cambios implican una innovación. De esta forma, las innovaciones no son necesariamente una postulación de ideas nuevas y fascinantes, sino que también pueden ser cambios y/o adopciones de nuevas prácticas que modifiquen protocolos previamente establecidos (Paz y Fontaine, 2017).

Ahora bien, una de las dificultades con este concepto es que puede referirse tanto a procesos de invenciones de políticas públicas, a procesos de difusión y/o transferencia de políticas, evaluación y cambios de la política o de algún componente de la misma (Paz y Fontaine, 2017). Es por lo anterior, que Hall (1993) distingue dos enfoques fundamentales para comprender el cambio y la innovación para el análisis de las políticas públicas. El primero de ellos es la esfera de los objetivos o fines perseguidos (goals), estos son entendidos como los objetivos generales que guían la política en un campo en particular. En segundo lugar, Hall menciona las técnicas de la política (techniques) estos son todos los instrumentos que presenta la política pública para alcanzar los objetivos. De igual forma, Harguindéguy (2013) aborda la tensión existente entre fines perseguidos y medios, siendo los primeros definidos como aquellos que dan justificación a la política pública en cuestión, es decir todos aquellos objetivos y misión presentes en la política, que pueden tener un carácter implícito y/o explícito. Por otra parte, los medios son entendidos como aquellos recursos necesarios para llevar a cabo la política pública, es decir todos los instrumentos creados para cumplir los fines u objetivos, estas pueden ser: instituciones, personal, presupuesto asignado e incluso cada uno de los mecanismos presentes en la política pública.

Por otra parte, Cashore y Howlett $(2007 ; 2009)$ profundizan en la distinción realizada por Hall (1993), complementando los componentes previamente mencionados, entregando una nueva dimensión referida al nivel de abstracción. Este será alto cuando se está hablando de la filosofía o fin implícito perseguido por la política, así como también cuando nos referimos a la lógica instrumental. El nivel de abstracción es medio cuando nos planteamos los objetivos explícitos en el programa, así como también los mecanismos para lograr alcanzar dichos objetivos. Y finalmente, hablamos de un nivel de abstracción bajo cuando estamos en presencia de las organizaciones que promueven los fines y los mecanismos de calibración que hacen posible la entrega de los beneficios, actividades o acciones de una política pública Cashore y Howlett (2007; 2009).

Entonces, siguiendo a Cashore y Howlett $(2007 ; 2009)$ es posible distinguir seis elementos relevantes que nos permitirán comparar los programas, y en este caso, además, identificar qué aspectos fueron posiblemente transferidos 
desde el programa CHS a los otros casos de estudio. En primer lugar, encontramos los fines, estos tienen relación con el objetivo implícito buscado por la política pública, su filosofía y/o visión de sociedad a construir. Segundo, encontramos los objetivos, estos son planteados de forma explícita dentro de la definición de la política pública. En tercer lugar, definimos organización como la institución encargada o responsable de la política pública (Cashore y Howlett, 2009). Cuarto, la lógica instrumental entendida como aquellas instituciones encargadas de ejecutar y dar cuerpo a la política pública, es decir, leyes, organismos ejecutores y/o los dispositivos selección de beneficiarios. En quinto lugar, los mecanismos presentes en la política pública, entendidos como aquellos instrumentos utilizados por la política para lograr cumplir con los objetivos planteados, estos pueden ser bonos, subsidios, accesos, entre otros. Finalmente, la calibración se refiere a aquellos aspectos menores y de carácter más normativo dentro de la política pública y de los mecanismos en sí, estos pueden ser, por ejemplo: la penalización o egreso de un programa social (Cashore y Howlett, 2009 y Harguindéguy, 2013).

Esta distinción entre fines y medios facilita el análisis comparado y permitirá observar la coherencia interna - entre los primeros y los segundos- de los programas. Para ello, también se considerará la propuesta de Sottoli (2002), quien ha identificado tres paradigmas que inspiran las políticas sociales en América Latina y que se encuentran vinculados a los modelos de desarrollo impuestos: tradicional o pre reformas económicas, el paradigma post reformas estructurales y el paradigma de la política social emergente (que es el paradigma vigente) (Sottoli, 2002:51). Su propuesta define dimensiones de análisis tales como los objetivos de las políticas sociales, su ideario social, las prioridades de las políticas sociales, la institucionalidad y los destinatarios, entre otros aspectos. El supuesto es que los programas ubicados en determinado paradigma debieran poseer una coherencia con las dimensiones consideradas, lo que contribuirá a nuestro análisis.

Junto con ello, la propuesta de análisis entre fines y medios, permitirá identificar en qué ámbito se desarrolla la posible transferencia de innovación. Ello se torna relevante ya que si esta se ubica en los fines o medios, ello tiene implicancias para el diseño de los programas y en el nivel de cambio posible. La introducción de innovaciones a nivel de los medios en un ámbito de abstracción bajo, resulta menos significativo que a nivel de los fines y abstracción alta. En consecuencia, esta propuesta permite ponderar la relevancia de la posible transferencia y asimismo posibilita futuras preguntas respecto a las características de los Estados que los adoptan. Por ejemplo, es posible considerar 
la relación entre sus capacidades estatales ${ }^{7}$ y las innovaciones adoptadas y si por tanto constituyen variables que podrían explicar particularidades en los tipos de programas diseñados en los países de la región.

\section{PROPUESTA METODOLÓGICA}

Este trabajo presenta un estudio de análisis comparado de tres programas de transferencia condicionada: Chile Solidario en Chile, el Programa Tekoporá en Paraguay y Familias en Acción de Colombia. El período analizado comprende el momento de adopción e implementación inicial de los PTC de estos países, esto es, entre el año 2000 y el año $2012^{8}$. La perspectiva comparada permitirá establecer con claridad las principales diferencias y similitudes en estos programas, su coherencia entre fines y medios e identificar si hubo transferencia de componentes entre los programas.

La selección del caso del Programa Chile Solidario como "caso guía" se debe a que presenta una serie de innovaciones dentro de sus instrumentos y sus objetivos, que pudieron ser un elemento transferido hacia otros programas de iguales características (Valencia, 2008 y Peck, 2015). En particular, se puso atención a la ya mencionada innovación del acompañamiento sicosocial, que surge con el CHS. En ese sentido, debido a que Paraguay y Colombia se encuentran dentro del $33 \%$ de los programas que poseen un componente de apoyo psicosocial, se escogieron como casos a comparar. Junto con ello, la literatura señala que el programa innovó en cuanto a que su diseño implicaba un trabajo intersectorial entre sectores sociales, generando un proceso de coordinación interministerial (Larragaña, Contreras y Cabezas, 2015).

Para llevar a cabo la comparación entre los programas, a partir de la bibliografía referida de fines y medios (Hall, P. 1993; Howlett, M. y Cashore, B. 2009; Harguindéguy, 2013) se realizó una matriz de análisis que incluye las dimensiones de las políticas a considerar, así como su nivel de abstracción. Esto es, considerar los fines perseguidos (Fines, Objetivos y Organización) y los Medios (Lógica Instrumental, Mecanismos y Calibración). Cada caso es desarrollado describiendo los principales hitos del proceso de formulación de los programas y luego las matrices fueron completadas a partir de la información primaria y secundaria recopilada (documentos oficiales, artículos académicos, sitios web, entre otros). Esta información fue complementada con 21 entrevistas semiestructuradas en terreno a expertos, académicos y funcionarios públicos de Colombia y Paraguay entre mayo y octubre de 2018 (ver listado en anexo). 


\section{DESCRIPCIÓN Y ANÁLISIS DE LOS PROGRAMAS DE \\ TRANSFERENCIA CONDICIONADA: CHILE, COLOMBIA Y PARAGUAY}

5.1. CHILE: PROGRAMA CHILE SOLIDARIO

El Chile Solidario nace el año 2002, durante el gobierno de Ricardo Lagos, con el objetivo de promover la integración de las familias en situación de extrema pobreza a las redes sociales del Estado y su acceso a mejores condiciones de vida (Ley 19.949, 2004). Constituyó el principal instrumento de la política social para la superación de la pobreza hasta el año 2010, atendiendo el año 2008 a 332.995 familias (CEPAL, 2011). El programa dependía del Ministerio de Desarrollo y Planificación Social (MIDEPLAN) (hoy Ministerio de Desarrollo Social). El CHS fue concebido como un Sistema de Protección Social, y al mismo tiempo ha sido calificado como un programa de transferencia condicionada? . Su componente más importante era el Programa Puente, dependiente del Fondo de Solidaridad e Inversión Social (FOSIS).

La identificación de los beneficiarios se realizaba a través de la Ficha de Protección Social, instrumento de estratificación socioeconómica que se utilizaba para identificar, priorizar, y seleccionar potenciales beneficiarios a los programas sociales ${ }^{10}$. El Ministerio informaba a los municipios el puntaje de corte y los cupos de beneficiarios disponibles para cada comuna y estos invitaban a las familias a participar (Decreto 235, 2005).

El programa CHS presentaba condiciones en siete grandes dimensiones o categorías de la vida familiar: Identificación, Salud, Educación, Dinámica Familiar, Habitabilidad, Trabajo e Ingresos (Decreto 235, 2005). De estas dimensiones emerge un conjunto de 53 condiciones mínimas que deben ser cumplidas al momento del egreso de los dos años de apoyo psicosocial. Quienes cumplieran estas condiciones de elegibilidad contaban con el acceso expedito a un conjunto de transferencias monetarias estatales existentes previas al $\mathrm{CHS}^{11}$. Asimismo, recibían el Bono de Protección Social y el de Egreso, que eran transferencias específicas vinculadas al CHS (Decreto 235, 2005).

Una vez convocadas, las familias debían acceder a participar primero en el programa Puente a través de un "Contrato Familiar", donde se comprometían a cumplir los 53 objetivos mínimos exigidos por el programa (Decreto 235, 2005). A partir de ese momento, eran considerados parte del Sistema de Protección Social Chile Solidario, recibirían los subsidios monetarios del Estado y el acceso preferente a los programas sociales con el principal objetivo fortalecer el grupo familiar y acercarlo a las redes de protección del Estado ${ }^{12}$.

El componente central e innovador del CHS era el acompañamiento y trabajo personalizado que recibía - durante dos años, a través de un profesional o téc- 
nico social (Apoyo Familiar). - cada familia participante a través del Programa Puente. El objetivo era fortalecer las capacidades del grupo familiar a través del apoyo psicosocial, promover el desarrollo de las habilidades personales y familiares necesarias para satisfacer los mínimos exigidos por el programa y facilitar el acceso a la red de programas sociales que ofrecía el Estado (Larragaña, Contreras y Cabezas, 2015).

Junto con ello, esta atención personalizada estaba destinada también a fortalecer la vinculación efectiva de los beneficiarios con las redes locales y el acceso a los beneficios que están a su disposición. En consecuencia, se buscaba tender un "puente" entre las familias y el Estado, que contribuyera a la superación de la pobreza (Larragaña, Contreras y Cabezas, 2015; Osorio, 2014). El acompañamiento se efectuaba durante 24 meses y se componía de un sistema de sesiones de trabajo periódicas con las familias o personas en su domicilio (Decreto 235, 2005). Los monitores eran los encargados de ingresar la información relativa a las sesiones de trabajo realizadas con las familias, consignando sus avances y resultados en el sistema de registro y monitoreo del CHS.

Para la implementación y ejecución de esta política, existió un alto proceso de coordinación interministerial o intersectorialidad (Larragaña, Contreras y Cabezas, 2015), estableciendo responsabilidad política y técnica en el Ministerio de Desarrollo y Planificación. Este ministerio, hoy Ministerio de Desarrollo Social, gestionaba los recursos financieros, coordinaba la red de instituciones participantes, administraba el registro de información y recolectaba datos para su evaluación. Por otra parte, FOSIS participaba como responsable del Programa Puente, que contaba con flexibilidad en su gestión y con una estructura que cubrió el país tanto a nivel regional como a nivel municipal por medio de las Unidades de Intervención Familiar (UIF) (Larragaña, Contreras y Cabezas, 2015).

La oferta de prestaciones sociales a que accedían las familias participantes en Chile Solidario estaba supeditada a programas que dependían de ministerios y servicios públicos, con los cuales MIDEPLAN establecía convenios a nivel central. Esta instancia de coordinación intersectorial, resultó particularmente interesante, dado su carácter innovador, para los países de la región y la banca internacional (Especialista en Protección Social del Banco Mundial, 2018). 


\section{Tabla 2.}

\section{Matriz de análisis Programa CHS}

\begin{tabular}{|c|c|c|}
\hline Componentes & $\begin{array}{l}\text { Aspectos } \\
\text { de la política }\end{array}$ & Programa CHS \\
\hline \multirow[t]{3}{*}{$\begin{array}{l}\text { Fines } \\
\text { perseguidos }\end{array}$} & Fines & $\begin{array}{l}\text { Abordar e integrar a un sistema de protección social al núcleo duro } \\
\text { de la pobreza en Chile. }\end{array}$ \\
\hline & Objetivos & $\begin{array}{l}\text { Otorgar apoyo integral a familias en condiciones de pobreza extrema } \\
\text { integrándolas a las redes sociales del Estado. }\end{array}$ \\
\hline & Organización & $\begin{array}{l}\text { - Ministerio de Desarrollo y Planificación (MIDEPLAN). } \\
\text { - FOSIS. } \\
\text { - Coordinación intersectorial. }\end{array}$ \\
\hline \multirow[t]{3}{*}{ Medios } & $\begin{array}{l}\text { Lógica } \\
\text { instrumental }\end{array}$ & $\begin{array}{l}\text { - Ley no } 19.949 \\
\text { - Identificación beneficiarios mediante Ficha de Protección Social. } \\
\text { - Programa de entrada Puente a cargo del Fondo de Solidaridad } \\
\text { e Inversión Social (dependiente de MIDEPLAN). }\end{array}$ \\
\hline & Mecanismos & $\begin{array}{l}\text { - Bono de protección a las familias que reciben el acompañamiento. } \\
\text { - Bono de egreso, al cumplir condiciones mínimas. } \\
\text { - Subsidio Único Familiar (SUF) Transferencia plana, sin condiciones y } \\
\text { menores de } 18 \text { años, mujeres embarazadas, deficientes mentales } \\
\text { e inválidos). } \\
\text { - Subsidio Agua Potable. } \\
\text { - Subsidio Pro-Retención Escolar y Pensión Básica Solidaria } \\
\text { (mayores } 65 \text { años). } \\
\text { - Apoyo a Familias para el Autoconsumo. } \\
\text { - Subsidio Cédula Nacional de Identidad. } \\
\text { - Acompañamiento sicológico. } \\
\text { - Acceso preferencial a otros programas sociales en los cuales } \\
\text { son elegibles. }\end{array}$ \\
\hline & Calibración & $\begin{array}{l}\text { - Duración dos años (24 meses) en el programa Puente } \\
\text { - Duración tres años (36 meses) en el programa CHS }\end{array}$ \\
\hline
\end{tabular}

Fuente: elaboración propia en base a la información del programa.

A comienzos del año 2012, el Programa Chile Solidario fue modificado por el programa Ingreso Ético Familiar, el cual conservó algunas de sus características, ya que "también constituye una política intersectorial de combate a la pobreza extrema con sede en el Ministerio de Desarrollo Social (MDS, ex Mideplan), con ejecución descentralizada en los municipios y con un componente de apoyo psico-social a las familias participantes. Sin embargo, innova al incluir un 
conjunto de transferencias monetarias condicionadas y no condicionadas, un componente de apoyo socio-laboral orientado a generar competencias laborales, y el Programa Eje que adapta la intervención a las características de cada familia y monitorea su desarrollo" (Larragaña, Contreras y Cabezas, 2015: 2).

\subsection{COLOMBIA: FAMILIAS EN ACCIÓN}

Familias en Acción surge durante el año 2000 con el fin de beneficiar a las familias, con integrantes menores de 18 años, en situación de pobreza y vulnerabilidad en Colombia. Originalmente, se planteó como una alternativa para mitigar los efectos de la crisis que vivió el país a finales de los años noventa (Benson, A. 2012: 57) y se diseñó como un programa temporal enfocado en municipios rurales y pequeños, es decir, aquellos con menos de 100 mil habitantes. Sin embargo, a partir de 2007 se expandió a municipios con más de 100 mil habitantes y actualmente es un programa permanente y de cobertura nacional, sustentado por la Ley No 1.532 de 2012 (Medellín y Sánchez, 2015).

Adicionalmente, en el año 2007 se creó de forma definitiva la Red de Protección Social para la Superación de la Pobreza Extrema (JUNTOS ${ }^{13}$ ) la cual busca que 1,5 millones de familias puedan superar la pobreza extrema, dándoles la opción de acceder a los diferentes programas sociales que ofrece el Estado, y ayudándolas a mejorar sus condiciones de vida (Ministerio de Educación, 2007). Para cumplir con este fin la Red Juntos estableció un funcionamiento por medio de dos estrategias, la primera corresponde al acompañamiento familiar, mientras que la segunda corresponde a la coordinación de las entidades gubernamentales (Agencia Presidencial para la Acción Social y la Cooperación Internacional, 2010).

El programa Familias en Acción presenta como característica principal la transferencia monetaria — bono- bajo corresponsabilidad que cada beneficiario debe cumplir y que es verificada a través del Ministerio de Salud y Educación cada dos meses. Mientras que la Red Juntos genera la entrega de acompañamiento social por medio de gestores y el cumplimiento de 45 logros básicos ${ }^{14}$.

Respecto a los componentes de Familias, el monitoreo resulta clave a la hora de poder focalizar de forma oportuna el beneficio y entregarlo a quien la requiere. Por lo tanto, el programa dentro de su gestión también cuenta con ciertos criterios básicos, asistencia escolar y controles médicos, que se deben cumplir para permanecer como beneficiario, o de lo contrario, no se le hará entrega de la transferencia. Para la Red Juntos, es muy importante la generación de intersectorialidad institucional, con el fin de lograr coordinar los recursos e insumos necesarios para la ejecución de la Red Juntos. Sin embargo, este proceso ha presentado una 
serie de dificultades institucionales, pues han existido problemas de articulación entre las diferentes entidades estatales debido a que cada una de ellas maneja objetivos, instrumentos, presupuestos y población beneficiaria particulares y no integrados (Funcionario (a) Dirección de Transferencias Condicionadas, 2018).

En el año 2012, el programa se rediseña en los siguientes puntos: actualización de los criterios de focalización, diseño diferencial de las transferencias monetarias por criterios geográficos y por grado educativo, transición y condiciones de salida. Por último, cambia su nombre a programa Más Familias en Acción (Angulo \& Gómez, 2014)

\section{Tabla 3.}

Matriz de análisis programa Familias en Acción

\begin{tabular}{|c|c|c|}
\hline Componentes & $\begin{array}{l}\text { Aspectos } \\
\text { de la política }\end{array}$ & Programa Familias en Acción \\
\hline \multirow[t]{3}{*}{$\begin{array}{l}\text { Fines } \\
\text { perseguidos }\end{array}$} & Fines & $\begin{array}{l}\text { Aumentar y fortalecer el capital humano de niños en extrema pobre- } \\
\text { za, entendiendo este proceso como un beneficio a largo plazo en la } \\
\text { disminución de esta misma. }\end{array}$ \\
\hline & Objetivos & $\begin{array}{l}\text { Impulsar la asistencia a los controles de crecimiento y desarrollo de } \\
\text { los niños y niñas menores de } 6 \text { años. } \\
\text { Contribuir a la disminución de la desigualdad y al cierre de brechas } \\
\text { regionales urbano-rurales y centro-periferia. }\end{array}$ \\
\hline & Organización & $\begin{array}{l}\text { - Presidencia de la República. } \\
\text { - Departamento Administrativo para la Prosperidad Social (desde 2012). } \\
\text { - Ley } n^{\circ} 1.532 \text { (desde 2012). }\end{array}$ \\
\hline \multirow[t]{3}{*}{ Medios } & $\begin{array}{l}\text { Lógica } \\
\text { instrumental }\end{array}$ & $\begin{array}{l}\text { - Sistema de Identificación de Potenciales Beneficiarios de Programas } \\
\text { Sociales (SISBEN). } \\
\text { - Sistema de Información de Población Desplazada (SIPOD). } \\
\text { - Departamento Administrativo para la Prosperidad Social. } \\
\text { - Censo indígena. } \\
\text { - Grupos internos de trabajo. }\end{array}$ \\
\hline & Mecanismos & $\begin{array}{l}\text { - Bono de educación, para hijos/as entre } 11 \text { y } 18 \text { años. } \\
\text { - Bono de salud para familias con niños menores de } 6 \text { años. } \\
\text { - Incentivo niños estudiantes con discapacidad. } \\
\text { - Incentivo de educación individual a familias con niños, niñas o adoles- } \\
\text { centes entre } 4 \text { y } 18 \text { años de edad que estén en el sistema escolar. }\end{array}$ \\
\hline & Calibración & $\begin{array}{l}\text { - Permanencia dos años. } \\
\text { - Chequeos médicos periódicos acorde la edad de los niños. } \\
\text { - } 80 \text { \% de asistencia a las escuelas. } \\
\text { - Pago bimestral. }\end{array}$ \\
\hline
\end{tabular}

Fuente: elaboración propia en base a la información del programa. 


\subsection{PARAGUAY: PROGRAMA TEKOPORÁ}

El programa Tekoporá (palabra guaraní que en español significa «vivir bien», iniciado el año 2005, correspondía a un programa de ingreso que tiene como objetivo general mejorar la calidad de vida de las personas beneficiadas, otorgando la posibilidad de que se ejerzan los derechos de alimentación, salud y educación, a través del aumento en el uso de servicios básicos y fortaleciendo las redes sociales, de manera de interrumpir el traspaso intergeneracional de la pobreza (Director(a) Tekoporá, 2018). Los objetivos específicos constan, en primer lugar, de brindar el apoyo socio familiar y comunitario que se requiere, mediante el acompañamiento sistemático, lo que facilitará el cumplimiento de las corresponsabilidades. En segundo lugar, crear capacidades de trabajo familiar, comunitario y cuyas condiciones permitan la participación ciudadana. Y, en tercer lugar, aumentar los recursos financieros de los hogares (Secretaría de Acción Social, 2016; Director(a) Politicas Sociales, 2018).

El Programa Tekoporá cuenta con dos grandes grupos de componentes, los cuales son: "Acompañamiento Socio Familiar y Comunitario" y "Transferencias Monetarias con Corresponsabilidad (TMC)". El primero consiste en el apoyo que se entrega a las familias a través de facilitadores que las visitan y apoyan y facilitan el cumplimiento de las corresponsabilidades por parte de las familias. A través de lo anterior, se brindan recomendaciones para mejorar el hábitat familiar, los hábitos de higiene, la calidad de los alimentos y la salud. En esta misma dirección, se orienta a las familias para que puedan acceder a los diferentes servicios públicos y, por tanto, fomentar las actividades comunitarias (Secretaría de Acción Social, 2016). El segundo componente, corresponde a la entrega de los recursos, los que son otorgados como subsidios financieros directos. Se realiza una entrega periódica de sumas de dinero a los hogares que se encuentran en situación de pobreza, pobreza extrema y vulnerabilidad. La entrega se realiza a una persona titular, el que puede ser la jefa o jefe de hogar, otorgando prioridad a las mujeres para que ejerzan como titular, dependiendo de la situación de cada familia. Los pagos de las Transferencias Monetarias se realizan en forma bimestral (Secretaría de Acción Social, 2016).

El año 2009, se firmó un convenio entre la Agencia Chilena de Cooperación Internacional (AGCl) y el Gabinete Social de la Presidencia de la República de Paraguay, que establecía el apoyo técnico de Chile en materia de estructuración e institucionalización del Gabinete Social y en la generación de un Sistema de Protección Social. El objetivo era instalar una red de protección social llamada "Paraguay para Todos», así como también, la puesta en marcha de una estrategia para la asistencia de familias denominada "Paraguay Saso Pyahu» 
o Paraguay Solidario ${ }^{15}$, la cual se inspiraba en la experiencia chilena con el Programa Chile Solidario (Ministerio de Relaciones Exteriores, 2009). No obstante, el convenio se ejecutó, el Sistema de Protección Social en Paraguay no se ha concretado hasta el día de hoy, pues se espera que este se encuentre en funcionamiento para el año 2023 (Unidad Técnica, 2018).

\section{Tabla 4.}

Matriz de análisis programa Tekoporá

\begin{tabular}{|c|c|c|}
\hline Componentes & $\begin{array}{l}\text { Aspectos } \\
\text { de la política }\end{array}$ & Programa Tekoporá \\
\hline \multirow[t]{3}{*}{$\begin{array}{l}\text { Fines } \\
\text { perseguidos }\end{array}$} & Fines & $\begin{array}{l}\text { Conformar una red de protección social que permita combatir la falta } \\
\text { de acceso a servicios por parte de la población pobre. }\end{array}$ \\
\hline & Objetivos & $\begin{array}{l}\text { El programa busca incrementar los recursos de los hogares titulares a } \\
\text { través de transferencias monetarias con corresponsabilidad, apoyo so- } \\
\text { cio familiar y comunitario, a través de un acompañamiento sistemático. }\end{array}$ \\
\hline & Organización & - Presidencia de la República. \\
\hline \multirow[t]{3}{*}{ Medios } & $\begin{array}{l}\text { Lógica } \\
\text { instrumental }\end{array}$ & $\begin{array}{l}\text { - Ficha Hogar de Selección de Beneficiarios. } \\
\text { - Decreto } n^{\circ} 7743 / 11 \text { (desde 2009). } \\
\text { - Ley no 4078/11 } \\
\text { - Secretaria de Acción Social. }\end{array}$ \\
\hline & Mecanismos & $\begin{array}{l}\text { - Soporte Alimentario. } \\
\text { - Bonos económico salud. } \\
\text { - Bonos económico educación. } \\
\text { - Beneficios sin condicionalidad a adultos mayores. } \\
\text { - Apoyo económico a personas con discapacidad. } \\
\text { - Acompañamiento social y familiar. }\end{array}$ \\
\hline & Calibración & - Permanencia seis años. \\
\hline
\end{tabular}

Fuente: elaboración propia en base a la información del programa.

\subsection{ANÁLISIS COMPARADO DE LOS PROGRAMAS}

Sistematizadas ya las características de los PTC en estudio, se presenta ahora el análisis comparado en base a la matriz propuesta. Este ejercicio permite contrastar las diferencias y similitudes entre los programas, su coherencia e identificar posibles transferencias desde el programa Chile Solidario a los otros programas. 
En primer lugar, el análisis demuestra que, si bien todos los programas son calificados como Programas de Transferencias Condicionadas y desde allí se podría asumir que son iniciativas homogéneas, ello es una afirmación que requiere una discusión (ver Tabla 5). En ese sentido, es efectivo que poseen componentes y características comunes, que se ubican en el ámbito de los medios. Sin embargo, los tres programas presentan diferencias en el ámbito de los fines perseguidos. Chile Solidario señala que su fin es «abordar e integrar a un sistema de protección social al núcleo duro de la pobreza en Chile», el programa Familias en Acción indica «aumentar el capital humano de niños en extrema pobreza", mientras que el programa Tekoporá plantea "combatir la falta de acceso a servicios de educación y salud por parte de la población pobre». Así, se observa que la amplitud de estos fines es diversa, y se ubican en el ámbito estructural de la vinculación con el Estado y la disponibilidad de acceso a los servicios por este provisto, o situaciones que se remiten a las capacidades individuales, tales como el capital humano. Junto con ello, si se considera la propuesta de Sottoli (2002) acerca de los tres paradigmas que inspiran las políticas sociales en América Latina en las últimas décadas, el análisis de los fines denota que los programas se ubican en paradigmas distintos. Por una parte, el CHS, se ubicaría en el paradigma emergente, donde las prioridades de la política social son, además de "la lucha contra la pobreza, nuevos temas tales como la equidad, integración social de grupos excluidos (...) calidad de los servicios sociales entre otros" (Sottoli, 2002: 50). En el caso del programa Tekoporá, se ubicaría en el paradigma post reforma estructural, ya que su fin es coherente con la prioridad de la "lucha contra la pobreza a través de programas sociales compensatorios y focalizados" (Sottoli, 2002: 50).

Al observar los objetivos del programa, en el caso del CHS y de Familias en Acción, estos son coherentes con los fines propuestos, ya que en el caso de Chile Solidario se plantea, "otorgar apoyo integral a familias en condiciones de pobreza extrema" y en el caso del segundo "fomentar la participación de las familias más pobres en salud y educación, para formar capital humano y contribuir a la disminución de la desigualdad y al cierre de brechas regionales urbano-rurales y centro-periferia". En el caso de Tekoporá, los objetivos son "proporcionar subsidios directos y subsidios indirectos a las poblaciones más pobres». En esa línea, estos objetivos apuntan a mejorar la situación económica de las familias, pero no se vinculan de manera directa con el acceso a los servicios en salud y educación. Junto con ello, se sitúan más bien en los objetivos del paradigma post reformas estructurales, el cual era el combate a la pobreza. Mientras que los objetivos del paradigma emergente son la reducción 
de la exclusión social y el aumento de la equidad social, los cuales presentan mayor coherencia con lo señalado por el CHS y Familias en Acción.

En ese sentido, los programas presentarían coherencia entre sus fines y objetivos explicitados, pero se observa divergencia en la complejidad y amplitud del ámbito de acción señalado. Ello queda en evidencia al contrastarlo con la propuesta de Sottoli (2002) y ubicarlos en los paradigmas de políticas sociales. En ese sentido, programas que emergieron en un período temporal cercano y que cuentan con componentes a nivel de los medios similares, apuntan a fines y prioridades de políticas sociales divergentes.

En relación a la organización definida para avanzar en la concreción del fin propuesto, se observa que sólo en el caso de Chile, el programa depende de un ministerio especializado en la temática. Sin embargo, existe participación tanto de diversos ministerios como de los municipios. En el caso de Colombia, se aprecia un alto nivel de institucionalización, pero con un bajo nivel de coordinación interministerial, esto se puede observar en la falta de "engranaje» entre las instituciones a cargo del programa Familias en Acción y la Red Juntos (Funcionario (a) Dirección de Transferencias Condicionadas, 2018). En el caso de Paraguay, existe un bajo nivel de capacidad institucional y de coordinación, ya que el programa depende exclusivamente de la Presidencia. Ello, eventualmente pone en riesgo su continuidad cuando se generan cambios de gobiernos, así como no se asegura la sistematicidad de la información. Ello, ya que son "estructuras altamente subordinadas a estas fluctuaciones políticas; "en estos casos, el riesgo de una escasa sostenibilidad política resulta considerable" (Cechinni y Martínez, 2011:60). Adicionalmente, no han contado con la capacidad institucional para implementar un sistema de protección social que auné los componentes de los diversos programas sociales y de transferencia condicionada (Unidad Técnica, 2018).

Al analizar los medios utilizados para implementar los programas, se observa un poco más de similitud que en los fines comentados, si bien en la lógica instrumental se aprecia una divergencia vinculada a lo ya dicho. Esto, ya que en el caso chileno existe una Ley (Ley 19.949) que respalda la continuidad y financiamiento el programa, junto con la dependencia de dos organismos especializados (MIDEPLAN y FOSIS). En el caso de Tekoporá su funcionamiento está definido mediante el decreto No 7743 y la Ley No 4078/11 que regula específicamente los programas de transferencias monetarias condicionadas. Y tanto en este como en el caso de Colombia no dependen de ministerios especializados. Donde se observa una significa similitud es en cuanto a los principales mecanismos que contemplan estos programas para concretar sus objetivos. En los tres casos 
analizados se observan las transferencias monetarias (bonos), si bien en el caso de Tekoporá y Familias en Acción están condicionados al cumplimiento de las condiciones en educación y salud. En el caso chileno, también existe un bono, pero asociado a la incorporación al programa Puente y el cumplimiento de los 53 mínimos indicados. Así, los mecanismos son idénticos en el caso de Paraguay y Colombia, y levemente diversos con el caso chileno. Ahora bien, los tres programas consideran hoy, apoyo sicosocial a las familias. Ello pone en evidencia un cierto grado de incoherencia entre los fines, objetivos y medios. Retomando lo ya señalado en torno a los paradigmas, el programa Tekoporá explicitaría fines y objetivos que apuntan a la superación de la pobreza, pero integraría un medio, el acompañamiento sicosocial, que apunta a otros objetivos.

En esa misma línea argumental y complementando con lo planteado por Cecchini y Martínez, se observa que los países aspiran a que los programas se configuren como una iniciativa dentro de un sistema más complejo de protección social. Ello no se consigue en la misma magnitud, en todos los casos, pero los tres programas avanzaron, durante el período de estudio en esa línea. Lo significativo es que al incluir el componente de apoyo sicosocial, se busca constituir una iniciativa donde es "la propia oferta pública la que debe acercarse a las familias y no al revés, surgiendo la lógica de un sistema de oferta articulado y activo. Además, esto permite plantear una forma de superar la fragmentación programática e institucional y sentar las bases de una intervención intersectorial a través de un acceso único para el conjunto de programas y servicios sociales con la implementación de la "ventanilla única" de atención, que en el caso de Chile Solidario se materializa en la figura de los "apoyos familiares" (Cecchini y Martínez: 117). Según los autores, ello se conseguiría en un mayor grado en Chile, y en menor grado en Colombia y Paraguay. Esa afirmación es coincidente con lo que ya hemos señalado antes, en cuanto a que los fines del CHS apuntan a esta integración de las familias con el Estado y sus objetivos son coherentes con ello. No obstante, ello no se observa en los casos de Tekoporá y Familias en Acción. Si bien ambos han integrado el componente de apoyo sicosocial, no cumplen con la característica de que las «las condicionalidades quedan en un segundo plano ante la importancia otorgada al acompañamiento y apoyo psicosocial a las familias (Cecchini y Martínez, 2011:119). 
Tabla 5.

Análisis comparado según fines y medios

\begin{tabular}{|c|c|c|c|c|}
\hline Componentes & $\begin{array}{l}\text { Aspectos } \\
\text { de la } \\
\text { política }\end{array}$ & Programa CHS & Tekoporá & Familias en Acción \\
\hline \multirow[t]{3}{*}{$\begin{array}{l}\text { Fines } \\
\text { perseguidos }\end{array}$} & Fines & $\begin{array}{l}\text { Abordar e integrar a un } \\
\text { sistema de protección } \\
\text { social al núcleo duro de } \\
\text { la pobreza en Chile. }\end{array}$ & $\begin{array}{l}\text { Combatir la falta de acce- } \\
\text { so a servicios de educa- } \\
\text { ción y salud por parte de } \\
\text { la población pobre. }\end{array}$ & $\begin{array}{l}\text { Aumentar el capital huma- } \\
\text { no de niños en extrema } \\
\text { pobreza }\end{array}$ \\
\hline & Objetivos & $\begin{array}{l}\text { Otorgar apoyo integral a } \\
\text { familias en condiciones } \\
\text { de pobreza extrema } \\
\text { integrándolas a las redes } \\
\text { sociales del Estado. }\end{array}$ & $\begin{array}{l}\text { Proporcionar subsidios } \\
\text { directos y subsidios indi- } \\
\text { rectos o a las poblaciones } \\
\text { más pobres. }\end{array}$ & $\begin{array}{l}\text { Impulsar la asistencia a los } \\
\text { controles de crecimiento } \\
\text { y desarrollo de los niños y } \\
\text { niñas menores de } 6 \text { años. } \\
\text { Contribuir a la disminución } \\
\text { de la desigualdad y al } \\
\text { cierre de brechas regio- } \\
\text { nales urbano-rurales y } \\
\text { centro-periferia }\end{array}$ \\
\hline & Organización & MIDEPLAN & Presidencia & Presidencia \\
\hline \multirow[t]{3}{*}{ Medios } & $\begin{array}{l}\text { Lógica } \\
\text { instrumental }\end{array}$ & $\begin{array}{l}\text { - } \text { MIDEPLAN } \\
\text { - FOSIS } \\
\text { - Ley n } 19.949\end{array}$ & $\begin{array}{l}\text { - Decreto n } 1.928 \\
\text { - Secretaria de Acción } \\
\text { Social }\end{array}$ & $\begin{array}{l}\text { - Departamento Adminis- } \\
\text { trativo para la Prosperi- } \\
\text { dad Social. } \\
\text { - Ley No } 1532\end{array}$ \\
\hline & $\begin{array}{l}\text { Mecanismos } \\
\text { principales }\end{array}$ & $\begin{array}{l}\text { - Bonos. } \\
\text { - Subsidios. } \\
\text { - Apoyo psicosocial } \\
\text { - Acceso preferencial }\end{array}$ & $\begin{array}{l}\text { - Bono apoyo económico } \\
\text { salud. } \\
\text { - Bono apoyo económico } \\
\text { educación } \\
\text { - Acompañamiento social } \\
\text { y familiar. }\end{array}$ & $\begin{array}{l}\text { - Bono de educación. } \\
\text { - Bono de salud } \\
\text { - Acompañamiento } \\
\text { Familiar y comunitario } \\
\text { (desde el 2011) }\end{array}$ \\
\hline & Calibración & $\begin{array}{l}\text { Permanencia de dos } \\
\text { años }\end{array}$ & $\begin{array}{l}\text { Permanencia de seis } \\
\text { años }\end{array}$ & Permanencia de dos años \\
\hline
\end{tabular}

Fuente: elaboración propia en base a la información del programa. 
Por último, en relación al segundo objetivo de este trabajo, identificar los componentes que pudieron haber sido transferidos a partir del caso chileno (el primero que los incluyó en sus diseños), ya se ha indicado la presencia del apoyo sicosocial del CHS en los casos de Colombia y Paraguay. Esta característica aparece en los programas de la región desde la implementación en el año 2002 y como hemos visto constituye una fuerte innovación respecto al conjunto de estos, pues contempla la figura de un monitor encargado de acompañar y apoyar a las familias en el proceso de cumplimiento de las condiciones necesarias para obtener el bono y el fortalecimiento del entorno familiar. Así, en el caso del CHS, «los apoyos familiares tienen como objetivo básico el trabajo psicosocial y acompañamiento a los hogares beneficiarios por un espacio de 24 meses. Durante este tiempo, se invita a las familias a comprometerse en el mejoramiento de ciertos aspectos de su calidad de vida considerados mínimos sociales en términos de derechos de ciudadanía” (Cecchini y Martínez: 120). En el caso de Colombia, una vez que fueron implementados a partir del 2001 en la Red Juntos, los gestores sociales debían articular la oferta pública de servicios y programas sociales en torno a las familias y el trabajo para alcanzar determinados logros básicos (Cecchini y Martínez, 2011). Cabe destacar que ambos programas, Familias en Acción, no han sido integrados institucionalmente, pero en la práctica se complementa la entrega del bono monetario con el acompañamiento sicosocial, ambos procesos dependientes de programas e instituciones diferentes, causando duplicidad de información, para coordinar los presupuestos e integrar a las diversas instituciones (Asesor(a) Regional, 2018; Coordinador (a) Nacional, 2018; Funcionario (a) Dirección de Transferencias Condicionadas, 2018). Por último, en el caso del Tekoporá, los apoyos familiares cumplían diversos objetivos: el trabajo educativo y de capacitación a las familias en distintos temas de capital humano y de dinámica familiar, evaluación del cumplimiento de las condicionalidades en salud y educación, y analizar con las familias estrategias para potenciar el capital productivo tanto a nivel familiar como comunitario (Cecchini y Martínez, 2011). Así, se observa que estos apoyos implican actividades que complementan la entrega de la transferencia monetaria.

Lo interesante en cuanto a la coherencia de los programas es que estos han incluido un componente en el nivel de los medios similar al caso chileno, correspondiente al acompañamiento psicosocial, esto a pesar de no compartir los mismos fines y objetivos. La adopción de estos componentes, pareciera ser resultado de procesos de transferencia entre el programa chileno y Paraguay y Colombia. Se han identificado en los procesos de formulación instancias de 
cooperación internacional que nos señalan que hubo contactos formales a partir de las cuales se habría desarrollado un encuentro e intercambio de información entre los países y que podría haber incidido en la adopción del componente de apoyo sicosocial. Como ya se señaló en el caso de Paraguay (Tekoporá) incorpora desde el año 2011 un plan de asistencia familiar y comunitaria llamado "Bienestar comunitario en acción", en el marco del convenio firmado con la AGCI para la conformación del Paraguay Solidario. En ese sentido queda por abordar, para este caso y para el colombiano, si estas instancias de cooperación $\mathrm{u}$ otras que pudieron existir implicaron la transferencia de este componente, qué actores participaron en estos procesos y cuáles son los mecanismos de transferencia posible de identificar ${ }^{16}$.

\section{CONSTDERACIONES FINALES}

Los programas de Transferencia Condicionada nacen en América Latina a finales de los años noventa con el objetivo combatir la extrema pobreza y la falta de acceso a los servicios básicos. Estos programas presentan dos componentes comunes, el componente de condicionalidad para la entrega de beneficios y la entrega de bonos a la mujer jefa de hogar. Además, constatamos componentes innovadores tales como el apoyo psicosocial a las familias beneficiadas por los PTC.

El primer objetivo de este trabajo era analizar las características comunes y divergencias de los PTC en América Latina a través de una propuesta de análisis que distingue los fines y los medios de los programas. En esa línea, se identificaron los niveles en los cuales se encuentran los componentes a analizar de una política pública y se procedió a constatar y desagregar todos aquellos aspectos presentes en dichos componentes y en sus niveles de abstracción. Es así como se observó que existen sutilezas en la comprensión de los objetivos y fines perseguidos por las políticas públicas. Pues mientras unos responden a objetivos concretos, los fines se centran en núcleo duro de la política. De igual forma, sucede con los medios, donde fue posible identificar que existen diferencias entre los mecanismos y las calibraciones, los primeros entendidos como instrumentos de la política pública para dar cumplimiento a los objetivos. Mientras que los segundos son entendidos como todas aquellas sutilezas presentes en los mecanismos y que pueden variar sin afectar ni los mecanismos en sí, ni los objetivos. Por ejemplo, la duración de la entrega del beneficio, el monto entregado y/o la presencia de egreso. 
El segundo objetivo era identificar si existen componentes innovadores en el conjunto de programas y que pudieran haber sido objetivo de transferencia. Así, una de las innovaciones del programa Chile Solidario, el apoyo sicosocial, fue identificado, luego de un análisis general de los programas de la región, en los casos de Colombia y Paraguay. Ello sugiere, de manera potencial, un proceso de transferencia del componente del apoyo sicosocial dentro de la ola de difusión de PTC en América Latina (Osorio, 2015). En ese sentido, una pregunta plausible frente a esta temática se refiere a cuáles son las variables que explican que se desarrolle un proceso de transferencia desde Chile a países de América Latina. Además, es posible avanzar en los mecanismos mediante los cuales se efectuó la transferencia del componente de apoyo psicosocial a Paraguay y Colombia. Junto con identificar los actores presentes en el proceso los que pueden ser organizaciones donantes o expertos en políticas sociales.

Por último, también es preciso avanzar en analizar si las capacidades estatales pudieran marcar una diferencia en la adopción o no adopción de ciertos componentes. Los factores que explican las divergencias entre los programas de cada país no han sido discutidos de manera exhaustiva por la literatura. Se han atribuido a modo general a la variación en las características de cada proceso de formulación e implementación, y al contexto político, social y económico de cada país (Fiszbein y Schady, 2009), así como también a las capacidades administrativas y/o políticas que presente cada aparato público. Estas preguntas forman parte de las interrogantes que prosiguen a este trabajo, pero que no podían ser abordadas sin realizar este análisis comparado de los componentes de los programas. 
ANEXO

- Listado de Entrevistas

\begin{tabular}{|c|c|c|}
\hline Cargo & País & Fecha \\
\hline Ex Ministro de Planificación & Chile & 25 de mayo de 2018 \\
\hline Especialista en Protección Social del Banco Mundial & Chile & 22 de junio 2018 \\
\hline $\begin{array}{l}\text { Ex Director Agencia Presidencial para la Acción Social } \\
\text { y la Cooperación Internacional }\end{array}$ & Colombia & 27 de septiembre 2018 \\
\hline Ex Coordinador Nacional Red Juntos & Colombia & 27 de septiembre 2018 \\
\hline Encargado Seguimiento Programa Familias en Acción & Colombia & 25 de septiembre 2018 \\
\hline Ex Director General de Políticas Sociales & Paraguay & 4 de septiembre 2018 \\
\hline Ex Director General de Políticas Sociales & Paraguay & 4 de septiembre 2018 \\
\hline $\begin{array}{l}\text { Director de la Dirección Nacional del Plan de Estrategia } \\
\text { de Lucha contra la Pobreza }\end{array}$ & Paraguay & 5 de septiembre 2018 \\
\hline $\begin{array}{l}\text { Unidad Técnica Gabinete Social de la Presidencia } \\
\text { de la República }\end{array}$ & Paraguay & 5 de septiembre 2018 \\
\hline Coordinadora proyecto PNUD-SNBF Colombia & Colombia & 18 de octubre 2018 \\
\hline
\end{tabular}

Tabla 6.

Componentes esenciales PTC en América Latina 1990-2012 ${ }^{17}$

\begin{tabular}{lllc}
\hline Componentes & Descripción & $\begin{array}{c}\text { \% de países } \\
\text { que lo incluye } \\
\text { al adoptar PTC }\end{array}$ \\
\hline 1 & Condicionalidad Educación & $\begin{array}{l}\text { Asistencia de niños y adolescentes a } \\
\text { establecimientos educacionales }\end{array}$ & $100 \%$ \\
\hline 2 & Condicionalidad Salud & $\begin{array}{l}\text { Controles de salud al día para menores } \\
\text { de edad }\end{array}$ & 89\% \\
\hline 3 & $\begin{array}{l}\text { Entrega de Bono en dinero } \\
\text { a la jefa de hogar }{ }^{19}\end{array}$ & $\begin{array}{l}\text { Transferencia monetaria dado el } \\
\text { cumplimiento de las condiciones }\end{array}$ & $100 \%$ \\
\hline 4 & $\begin{array}{l}\text { Componente de apoyo } \\
\text { sicosocial }\end{array}$ & $\begin{array}{l}\text { Se refiere a si el beneficiario, junto con el } \\
\text { bono o el bien asignado, recibe apoyo sicoso- } \\
\text { cial a través de profesionales especializados }\end{array}$ & \\
\cline { 2 - 4 } & $\begin{array}{l}\text { El programa no incluye apoyo sicosocial } \\
\text { para las familias beneficiarias }\end{array}$ \\
\hline
\end{tabular}

Fuente: versión previa en Osorio, 2014. Fue elaborada en base a la clasificación de Cecchini y Martínez (2011), información disponible en Cecchini y Madariaga (2011) y la base de datos propia. 
Tabla 7.

Otras características PTC en América Latina 1990-2012

\begin{tabular}{|c|c|c|c|}
\hline & Características & Descripción & $\begin{array}{l}\text { \% de países } \\
\text { que lo incluye } \\
\text { al adoptar PTC }\end{array}$ \\
\hline 1 & $\begin{array}{l}\text { Mecanismo de identifica- } \\
\text { ción y focalización del } \\
\text { grupo de beneficiarios }\end{array}$ & $\begin{array}{l}\text { Comprobación de medios (Proxy means test). } \\
\text { Puede ser complementada con focalización } \\
\text { geográfica o a nivel de comunidades }\end{array}$ & $94 \%$ \\
\hline \multirow[t]{3}{*}{2} & Objetivos del programa ${ }^{20}$ & Apoyo monetario y desarrollo capital humano & $39 \%$ \\
\hline & & Desarrollo capital humano en niños y adolescentes & $61 \%$ \\
\hline & & $\begin{array}{l}\text { Inclusión de las familias a redes de apoyo estatal } \\
\text { y fortalecimiento capacidades psicosociales de } \\
\text { las familias }\end{array}$ & $39 \%$ \\
\hline \multirow[t]{2}{*}{3} & $\begin{array}{l}\text { Mecanismos de control } \\
\text { de las condicionalidades }\end{array}$ & $\begin{array}{l}\text { Reporte de los establecimientos de educación y } \\
\text { de salud o de los monitores especializados }\end{array}$ & $72 \%$ \\
\hline & & $\begin{array}{l}\text { Beneficiario lo reporta personalmente a oficinas en- } \\
\text { cargadas a las entidades encargadas del programa }\end{array}$ & $28 \%$ \\
\hline \multirow[t]{2}{*}{4} & Tipo de penalización & $\begin{array}{l}\text { Penalización blanda: advertencias y disminución } \\
\text { del beneficio }\end{array}$ & $56 \%$ \\
\hline & & $\begin{array}{l}\text { Dura: suspensión del beneficio luego de un } \\
\text { número específico de faltas }\end{array}$ & $44 \%$ \\
\hline \multirow[t]{2}{*}{5} & Institucionalidad ${ }^{22}$ & $\begin{array}{l}\text { Organismo responsable dependiente directamente } \\
\text { de la Presidencia }\end{array}$ & $44 \%$ \\
\hline & & $\begin{array}{l}\text { Organismo responsable adscrito al Ministerio ya } \\
\text { existente (Desarrollo Social, Pobreza, etc.) }\end{array}$ & $56 \%$ \\
\hline \multirow[t]{2}{*}{6} & $\begin{array}{l}\text { Pertenencia a un sistema } \\
\text { de protección social }\end{array}$ & $\begin{array}{l}\text { El programa es definido como un componente de } \\
\text { un sistema de protección social (vigente, creado } \\
\text { junto con el programa o posterior) }\end{array}$ & $56 \%$ \\
\hline & & $\begin{array}{l}\text { El programa no es definido como un componente } \\
\text { de un sistema de protección social }\end{array}$ & $44 \%$ \\
\hline
\end{tabular}

Fuente: versión previa en Osorio, 2014 y 2018. Fue elaborada en base a la clasificación de Cecchini y Martínez (2011), información disponible en Cecchini y Madariaga (2011) y la base de datos propia. 


\section{NOTAS}

${ }^{1}$ Este artículo es parte del Proyecto Fondecyt de Iniciación № 11160363 «¿Cómo viajan las ideas? La tecnocracia chilena como agente de transferencia de programas sociales a Guatemala y Paraguay". Investigadora Responsable: Cecilia Osorio. Agradecimientos a los ayudantes de investigación en Fondecyt Daniela Castillo, Camila Mistretta e Isaac Saldías.

2 Llamado también paradigma emergente (Franco, 1996) o paradigma nuevo post-reformas (Sottoli, 2002).

${ }^{3}$ Se ha considerado para el período en estudio, 1990-2012, la clasificación de 20 países de América Latina señalada por CEPAL: Argentina, Bolivia, Brasil, Chile, Colombia, Costa Rica, Cuba, Ecuador, El Salvador, Guatemala, Haití, Honduras, México, Nicaragua, Panamá, Paraguay, Perú, República Dominicana, Uruguay y Venezuela. De este grupo, sólo no los han implementado Cuba y Venezuela (León, Arturo, 2008; Fiszbein, Ariel y Schady, Norbert, 2009). También se observa experiencias en Centroamérica, África y otras ciudades del mundo, pero la concentración geográfica más significativa es en América Latina (Osorio, 2014, 2018)

${ }^{4}$ En El Caribe, Jamaica, San Kitts y Nevis, Santa Lucía, San Vicente y las Granadinas, Surinam y Trinidad y Tobago http://redproteccionsocial.org/ temas/puente-en-el-caribe (recuperado el 10 de noviembre de 2017).

${ }^{5}$ La selección de los casos se explica en apartado metodológico.

${ }^{6}$ La Asignación remplazó los programas de transferencia condicionada de ingresos más importantes de la primera década del presente milenio, principalmente el PJJHD, y el PF al establecer la incompatibilidad con otros programas de transferencia y concentrar las acciones solamente en la Asignación Universal por Hijo (Pautassi, Arcidiácono y Straschnoy, 2013).

${ }^{7}$ Existe un amplio debate acerca de la definición de capacidades estatales. Aquí seguiremos la definición de Alexandre de Ávila Gomide y Roberto Rocha C. Pires (2014), quienes identifican dos dimensiones: la técnica y la administrativa- política. Nos parece relevante aquí la dimensión técnica que se define cómo: i) la presencia de organizaciones con recursos humanos, financieros y apropiado tecnológico y que para la ejecución de las acciones; ii) la existencia y el funcionamiento de los mecanismos de coordinación (intra e inter-gubernamental); y iii) las estrategias de vigilancia (información de producción, supervisión y requisitos de rendimiento).

${ }^{8} \mathrm{~A}$ partir de ese último año, tanto el programa Familias en Acción y CHS, enfrentaron modificaciones significativas.

${ }^{9}$ La calificación como tal es un tema debatido, pero se le considera así ya que, si bien el bono no era el componente central del programa, se trató de un programa en el cual los beneficiaros debían comprometerse al cumplimiento de mínimos y otras actividades, y a cambio, recibirían el bono en dinero (Cecchini y Martínez, 2011). ${ }^{10} \mathrm{Con}$ la información obtenida a partir de la Ficha se calculaba un puntaje para las personas que se utilizaba para determinar si califica para los beneficios, subsidios o transferencias. Su vigencia era de dos años y su aplicación estaba a cargo de cada municipio. A partir de enero de 2016, la Ficha de Protección Social fue reemplazada por el Registro Social de Hogares, "sistema de información cuyo fin es apoyar los procesos de selección de beneficiarios de un conjunto amplio de subsidios y programas sociales. El Registro es construido con datos aportados por el hogar y bases administrativas que posee el Estado" http:// www.registrosocial.gob.cl/que-es-el-registrosocial/, recuperado el 21 de noviembre de 2018. ${ }^{11}$ Los subsidios que se entregan al beneficiario ya existían con anterioridad al programa: Subsidio familiar Ley $N^{\circ}$ 18.020, Pensiones asistenciales del decreto ley $N^{\circ} 869$, de 1975 , subsidio al pago del consumo de agua potable y de servicio de alcantarillado de aguas servidas de la ley $N^{\circ}$ 18.778 y al subsidio pro-retención escolar según la ley $N^{\circ}$ 19.873. Los bonos y el apoyo sicosocial son prestaciones nuevas que surgen con el programa: el Bono de Protección y el egreso están 
establecidos en el artículo $2^{\circ}$ transitorio de la ley $N^{\circ} 19.949$, y el apoyo sicosocial en el artículo $4^{\circ}$ de la ley No 19.949 (Decreto 235, 2005).

12 Respecto a los programas, distintas instituciones y organismos de las áreas de Salud, Educación, Trabajo, Vivienda, Justicia, entre otras, se comprometían con MIDEPLAN para darle prioridad a los beneficiarios de Chile Solidario. http:// www.chilesolidario.gob.cl/preg/07_preguntas.php Rescatado el 26 de abril de 2013.

13 Actualmente llamado Red Unidos.

${ }^{14}$ Los logros básicos (LB) constituyen el conjunto de condiciones mínimas deseables que una familia en pobreza extrema debe alcanzar para superar su situación. Con base en esto, la Red debe estructurar el acompañamiento familiar y comunitario, y gestionar la oferta de programas y servicios sociales hacia ellas. Estos 45 logros se encontraban contenidos en 9 dimensiones, las que iban desde la identificación hasta el apoyo para garantizar el acceso a la justicia (ANSPE, 2012).

15 Este programa fue implementado de forma paulatina hasta su concreción final el año 2012. de estudio considerando las características de los programas al año de adopción.

18 La mayoría de los programas exige la asistencia a los establecimientos educacionales para la enseñanza básica, pero alguno lo hacen para la secundaria. En cuanto a salud, algunos programas lo hacen para los menores de edad y otros incluyen además a mujeres embarazadas y personas de tercera edad. Se han asumido esas variaciones como aspectos menores, que no restan la centralidad de esta condicionalidad en educación y salud que se observa en toda la ola difusión.

${ }^{19}$ Es preciso señalar que el monto entregado varía entre un un 6\% y un 30\% del ingreso familiar. ${ }^{20}$ En el caso de los objetivos, no son categorías excluyentes (por lo que la suma de los porcentajes no da como resultado $100 \%$ ), ya que algunos países incluyen más de alguno de estos objetivos, y otros sólo uno de ellos.

${ }^{21}$ Es preciso consignar que en algunos programas no se especifica cómo se reporta el cumplimiento de la condicionalidad. En la mayoría de los programas lo reporta el establecimiento, por lo que se incluyeron en esa categoría.

22 Se han simplificado la amplia variedad de arreglos institucionales en estos dos grupos que destacan el nivel de autonomía del programa al depender de una estructura orgánica específica y no dependiente de un cambio de gobierno. 


\section{BIBLIOGRAFÍA}

A. de Ávila Gomide \& R. Rocha C. Pires (2014). "Capacidades Estatais e Democracia: Arranjos Institucionais de Políticas Públicas", Instituto de Pesquisa Econômica Aplicada (IPEA). Rio de Janeiro

Agencia Presidencial para la Acción Social y la Cooperación Internacional (2010). Lineamientos de la Cooperación Técnica entre Países en Desarrollo. Bogotá, Colombia

Angulo, R. \& Gómez, N. (2014). Inclusión social e inclusión productiva de los beneficiarios del programa Más Familias en Acción. Estudio de caso de Colombia. EUROsociAL, Guatemala. Retrieved from https://dds.cepal.org/redesoc/archivos_recursos/4371/Roberto Angulo_2014_Colombia.pdf

ANSPE (2012). Evaluación de Impacto de Juntos (hoy Unidos). Red de Protección Social para la Superación de la Pobreza Extrema. Informe de Evaluación.

Bender, K., Keller, S. \& Willing, H. (2014). "The Role of International Policy Transfer and Diffusion for Policy Change in Social Protection - A Review of the State of the Art». IZNE Social Protection Working Paper, 14/1.

Bennett, Colin. J. (1997). Understanding Ripple Effects: The Cross - National Adoption of Policy Instruments for Bureaucratic Accountability. Governance: An International Journal of Policy and Administration. Vol. 10 (3): 213-233.

(1991). "Review Article: What is Policy Convergence and What Causes It?" British Journal of Political Science, 21: 215-233.

Benson, A.L. (2012). "Efectos de Familias en Acción sobre la calidad de la oferta educativa”, Revista Desarrollo y Sociedad, 70. pp. 51-91.

BID (2016). Evaluación de impacto del programa tekopora. Banco Interamericano de Desarrollo (BID). Informe final en http://www.economia.gov.py/application/files/9514/7939/4429/ Evaluacion_de_Impacto_del_Programa_Tekopora_07062016.pdf

Cecchini, S. \& Atuesta, B. (s.f.). Programas de transferencias condicionadas en América Latina y el Caribe. Tendencias de cobertura e inversión. (Serie Políticas Sociales. No 224). Cepal Santiago.

Cecchini, S. (2009). "Desafíos de los programas de transferencias con corresponsabilidad». (Ponencia presentada en Panamá, 4 de junio de 2009). División de Desarrollo Social Comisión Económica para América Latina y el Caribe (CEPAL).

Cecchini, S. \& Madariaga, A. (2011). Programas de Transferencias Condicionadas. Balance de la experiencia reciente en América Latina y el Caribe. Santiago de Chile, CEPAL. 
CEPAL (2011). Programa de Transferencias Condicionadas. Base de datos de programas de protección social no contributivas América Latina y el Caribe. En http://dds.cepal.org/bdptc/

Cohen, Er. \& Rolando, F. (2006). Transferencias con corresponsabilidad. Una mirada latinoamericana. México. Secretaría de Desarrollo Social (SEDESOL).

Decreto 235 (2005). «Aprueba reglamento para la aplicación de la Ley № 19.949, que crea el Sistema de Protección Social denominado "Chile Solidario". Ministerio de Planificación y Cooperación. Fecha de Publicación Diario Oficial, 14 de marzo de 2005.

Dolowitz, D.P. \& Marsh, D. (2000). Learning from Abroad: The Role of Policy Transfer in Contemporary Policy-Making. Governance, 13(1), 5-23.

(1996). Who Learns What from Whom: a Review of the Policy Transfer Literature. Political Studies XLIV: 343-351

Dussauge, M. (2012). "La Transferencia de políticas como fuente de innovación gubernamental: promesas y riesgos» en Revista Chilena de Administración Pública, № 19, Santiago. pp. 51-79

Friszbein, A. \& Schady, N. (2009). Conditional cash transfers reducing present and future poverty. Washington D.C., Banco Mundial.

Franco, R. (1996). Los paradigmas de la política social en América Latina. Revista de la CEPAL, 58, 9-22.

Gomide, A., Boschi, R.R., \& Instituto de Pesquisa Econômica Aplicada (Eds.) (2016). Capacidades estatais em países emergentes: o Brasil em perspectiva comparada. Rio de Janeiro: Ipea.

Hall, P.A. (1993). "Policy Paradigms, Social Learning, and the State: The Case of Economic Policymaking in Britain» en Comparative Politics, Vol. 25 (3): 275-296

Harguindéguy, J.-B. (2013). Análisis de Políticas Públicas. Madrid: TECNOS.

Howlett, M. \& Cashore, B. (2007). Re-visiting the New Orthodoxy of Policy Dynamics: The Dependent Variable and Re-aggregation Problems in the Study of Policy Change. Canadian Political Science Review, 1(2), 50-62

- (2009). The Dependent Variable Problem in the Study of Policy Change: Understanding Policy Change as a Methodological Problem. Journal of comparative policy analysis: Research and Practice, 33-46.

Larrañaga, O.; Contreras, D. \& Cabezas, G. (2015). "Políticas contra la pobreza: de Chile Solidario al Ingreso Ético Familiar" en Las Nuevas Políticas de Protección Social en Chile. Santiago, Ed. Uqbar 
León, A. (2008). Progresos en la reducción de la pobreza extrema en América Latina. Dimensiones y políticas para el análisis de la primera meta del Milenio. Proyecto CEPALAECID. Seguimiento del componente de pobreza del primer objetivo de desarrollo del Milenio (AEC/06/003).

Ley 19.949 (2004). «Establece un Sistema de Protección Social para familias en situación de extrema pobreza denominado Chile Solidarion. Fecha de Publicación Diario Oficial, 5 de junio de 2004.

Marsh D. \& Sharman J.C. (2009). "Policy Diffusion and policy transfer" Policy Studies, 30:3, 269-288

Medellín, N. \& Sánchez Prada, F. (2015). ¿Cómo funciona Más Familias en Acción? Mejores prácticas en la implementación de Programas de Transferencias Monetarias Condicionadas en América Latina y el Caribe. Colombia: Banco Interamericano de Desarrollo.

Ministerio de Educación (2007). Gobierno lanzó red juntos, para superar la pobreza extrema, disponible en https://www.mineducacion.gov.co/cvn/1665/article-129034.html (rescatado en 2018)

Ministerio de Relaciones Exteriores (2009). Paraguay y la cooperación, AGCl, disponible en https://www.agci.cl/images/centro_documentacion/Bibliografia_Paraguay_mayo_2017.pdf (rescatado en 2018)

Newmark, A. (2002). An integrated approach to policy transfer and diffusion. The Review of Policy Research, Vol. 19 (2).

Osorio, C. (2014). "La difusión de los Programas de Transferencia Condicionada en América Latina 1990-2010", Doctorado en Ciencias Políticas y Sociales. Departamento de Ciencias Políticas y Sociales, Universitat Pompeu Fabra, Barcelona.

(2017). "Cómo viajan las ideas? El rol de las comunidades epistémicas en el diseño de políticas sociales en América Latina». CLAD 68, 75-112.

Paz, Bayron \& Fonteine, Guillaume (2017). A Causal Mechanism of Policy Innovation: The Reform of Colombia's Oil-Rents Management System. Revista de Estudios Sociales 63: 2-19. https://dx.doi.org/10.7440/res63.2018.01.

Pautassi, L; Arcidiácono, P. \& Straschnoy, M. (2013). Asignación Universal por Hijo para la Protección Social de la Argentina: Entre la satisfacción de necesidades y el reconocimiento de derechos. CEPAL \& UNICEF, Buenos Aires.

Page, E. (2000). Future Governance and the Literature on Policy Transfer and Lesson Drawing, Britannia House, London. 
Peck, J. \& Theodore, N. (2015). Fast Policy: Experimental Statecraft at the Thresholds of Neoliberalism. Minneapolis: Univ of Minnesota Press.

Presidencia de la República, Ministerio del Interior (2009). Decreto № 1799. Obtenido de Justicia Paraguay: http://paraguay.justia.com/nacionales/decretos/decreto-1799-apr-14-2009/ gdoc/

PNUD (2011). Mi Familia Progresa: Guatemala. Programa de las Naciones Unidas para el Desarrollo.

Przeworski, A. \& Teune, H. (1970). The logic of Comparative Social Inquiry. New York: Wiley. Interscience.

Secretaría de Acción Social (2016). Manual de trabajo para coordinación departamental y distrital del programa Tekopora. Asunción: Gobierno Nacional.

Sottoli, S. (2002). La política social en América Latina: diez dimensiones para el análisis y el diseño de políticas. Papeles de Población, 8(34).

Stone, D. (2001). "Learning Lessons, Policy Transfer and the International Diffusion of Policy Ideas". Centre for the Study of Globalisation and Regionalisation (CSGR), University of Warwick, United Kingdom.

Valencia, E. (2008). "Las Transferencias Monetarias Condicionadas Como Política Social en América Latina. Un Balance: Aportes, Límites y Debates" en Annual Review of Sociology, Vol. 34: 499-524.

\section{PARA CITAR ESTE ARTÍCULO:}

Osorio Gonnet, C. y Vergara Hermosilla, J.M. (2019). «Programas de transferencia condicionada frente a frente: Ios casos de Chile, Paraguay y Colombia (2000-2012)", DAAPGE, año 19, № 32 (ene-jun), 2019, pp. 109-140. Santa Fe, Argentina: UNL. 